\title{
Representações sociais, cultura e informação
}

\author{
Marco Antonio de Almeida \\ Doutor em Ciências Sociais pela Universidade Estadual de Campinas - UNICAMP \\ Professor do curso de Ciências da Informação e Documentação da FFCLRP/USP \\ E-mail: marcoaa@ffclrp.usp.br
}

BECKER, Howard. Falando da sociedade: ensaios sobre as diferentes maneiras de representar o social. Rio de Janeiro: Jorge Zahar, 2009. 312 p.

Howard Becker é sociólogo da escola de Chicago, conhecido por seus estudos inovadores, que transitam por discussões metodológicas, trabalhos sobre rotulação social, grupos marginais e sociologia visual e da arte. Nesses últimos terrenos, em particular, agregou à sua formação científica sua vivência como artista: também é fotógrafo e pianista de jazz, atividade que exerceu nos bares de Chicago para sustentar seus estudos. Apesar dessa trajetória interessante, o leitor pode estar se perguntando o que faz, afinal, uma resenha de um livro de sociologia numa revista de Ciência da Informação.

Falando da Sociedade: ensaios sobre as diferentes maneiras de representar o social discorre sobre o uso cotidiano de representações sociais. Nesse sentido, seu interesse estendese para além das fronteiras das Ciências Sociais, ao levantar questões sobre como as necessidades e práticas de organizações moldam nossas descrições e análises da realidade social. De que modo as pessoas que produzem, fazem circular e usam essas representações chegam a defini-las como adequadas? $\mathrm{O}$ foco de Becker são as intersecções e correlações entre os diferentes meios e formas de representar a sociedade. Para ele, problemas e soluções apresentados em distintas formas podem proporcionar uma "iluminação" recíproca. Assim, o livro está dividido em duas partes: a primeira, "Idéias", busca organizar as reflexões e teorias do autor acerca desses temas; a segunda, "Exemplos", aplica alguns dos conceitos e idéias elaborados anteriormente na análise de diversos tipos de representação: modelos matemáticos, textos científicos, diagramas, assim como filmes, fotografias, obras literárias e peças teatrais. Seu arco de referências aqui vai de acadêmicos e cientistas como Max Weber, Erving Goffmann, Thomas Kuhn e o matemático George Polya, até o fotógrafo Walker Evans, o dramaturgo George Bernard Shaw e os escritores Ítalo Calvino, George Perec e Jane Austen.

Representação social é algo que alguém nos conta acerca de algum aspecto da vida social. Tomando como ilustração dessa idéia a elaboração de mapas, o autor mostra como os 
mesmos são feitos para diversos objetivos, seja por leigos como a maioria de nós, em seu cotidiano, seja por profissionais especializadíssimos que combinam prática, raciocínio matemático, erudição científica e alta tecnologia. A partir desse exemplo, aborda uma questão de fundo: o poder de delimitação dos atores e das atividades consideradas "legítimas", entre o que é "científico" e o que não é, entre o que é "profissional" e o que não é, correlacionando o aumento da complexidade social aos processos de superespecialização que vivemos hoje.

Mas a principal aproximação de Becker à Ciência da Informação encontra-se na sua concepção sobre como se desenrola esse processo. Para ele, falar sobre a sociedade em geral envolve uma comunidade interpretativa, uma organização de pessoas que faz rotineiramente representações padronizadas de um tipo particular (os "produtores") para outros (os "usuários") que as utilizam rotineiramente para objetivos padronizados. Os produtores e os usuários adaptaram o que fazem ao que outros fazem - desse modo, a organização que compreende o fazer e o usar é, pelo menos por algum tempo, uma unidade estável, um mundo. A idéia de "mundo", relacionada a uma comunidade de produtores e usuários de representações sociais que configuram uma comunidade interpretativa, é recorrente na obra de Becker. Nesse sentido, ele aponta para o erro que é enfatizar substantivos em lugar de verbos. Em outras palavras: a concentração no objeto desvia nossa atenção para as capacidades formais e técnicas de um meio, enquanto que a atenção na atividade organizada mostra que aquilo que um meio pode fazer está relacionado às limitações organizacionais que afetam seu uso. Para diferentes organizações sociais, diferentes representações sociais. A organização molda não só o quê é feito, como também o quê os usuários desejam que as representações façam.

Ao analisar a construção e circulação de representações sociais, Becker mostra que toda representação da realidade social é parcial. Assim, interessa-lhe, sobretudo, as transformações pelas quais elas passam e o trabalho de seus usuários, mediados pelas instituições. Não à toa, um dos interlocutores constantes em seu texto é Bruno Latour, referenciado quando a discussão é acerca das modificações (translações) dos materiais, que segue determinada padronização ou convenção, e como o destino da representação estará na mão de seus usuários posteriores (especializados ou não). Becker aborda a tentativa de controle das utilizações posteriores dos usuários das representações construídas, introduzindo nelas restrições que limitem seus usos e interpretações. Para tanto, elabora uma lista de questões que poderia servir perfeitamente como roteiro para estudo de usuários e de circulação da informação. 
Em todos os casos, o dilema é como organizar o material, enfim, como construir a argumentação. Isso envolve procedimentos de seleção, de tradução, de arranjo, de interpretação. Becker utiliza como exemplos tabelas matemáticas e fotografias. No caso das primeiras, demonstra que, por si só, os números não dizem nada. O problema de ordenar os dados estatísticos é tornar visíveis as comparações relevantes, o que nos leva a refletir acerca da divisão e organização em categorias que permitam a comparação. A fotografia levanta problemas semelhantes. Por exemplo, em relação à seleção/ordenação das fotos: em que ordem dispor o material e como fazer o usuário respeitar essa ordem? Outro ponto: como lidar com a questão das legendas - interpretação do produtor - nas fotos? Após algumas reflexões, Becker afirma que a diferença entre tabelas estatísticas e fotografias é que o trabalho de interpretação, de organização dos dados em categorias já foi feito no primeiro caso, o que não ocorre no segundo. O âmbito das combinações possíveis não foi dado para as fotografias - e ele exemplifica isso com uma brilhante análise de fotos de mulheres norte-americanas em diferentes contextos. Ao final, conclui em relação às fotografias que todo esse trabalho de construir categorias de comparação e suas divisões, de criar hipóteses e checá-las, cabe ao usuário. O fotógrafo forneceu o material em estado "bruto" (engenhosamente escolhido e arranjado, sem dúvida), mas depois disso coube ao usuário construir a análise, com toda sua parafernália. Trata-se, portanto, de uma divisão do trabalho representacional muito diferente daquela envolvida na elaboração e no uso, por exemplo, de uma tabela do censo.

Ao ponderar que algumas representações da vida social exigem que seus usuários realizem uma grande quantidade de trabalho, Becker apresenta algumas questões importantes para todos aqueles que lidam com a informação e o conhecimento: Quantos usuários têm o conhecimento e as habilidades necessárias para fazer esse trabalho? Que acontece se não puderem ou não quiserem fazê-lo? Como levar os produtores de representações a lidar com a habilidade diferencial e a disposição dos usuários para fazer o trabalho que seus relatos exigem? Para o autor, dedicamos atenção às representações de acordo com a maneira pela qual aprendemos. Desse modo, algumas representações podem parecer óbvias para usuários que já sabem tudo que precisam para entender seu significado, enquanto outras são consideradas obscuras por demandarem mais "trabalho" interpretativo por parte dos usuários. Se todos nós tivemos algum tipo de treinamento, desde a infância, na interpretação de alguns objetos, essa experiência obviamente não contemplou todos os tipos de representação. Essas habilidades estão desigualmente distribuídas ao longo de todos os tipos de divisão social.

InCID: R. Ci. Inf. e Doc., Ribeirão Preto, v. 1, n. 2, p. 168-171, jul./dez. 2010. 
Becker vai demonstrando, ao longo do texto, que toda forma de representar conhecimento sobre a sociedade reduz a quantidade de dados com que os usuários têm de lidar. Saber tudo significa nada saber. O conhecimento resulta da eliminação de detalhes irrelevantes e da exposição da estrutura básica - a parte em que estamos interessados. Desse modo, como usuários, cortamos o que sentimos que podemos cortar e combinamos os fragmentos de informação agora sintetizados numa nova representação, o que nos possibilita maior controle sobre o que sabemos.

Falando da Sociedade: ensaios sobre as diferentes maneiras de representar o social enfim, levanta uma série de questões pertinentes e constrói reflexões instigantes para todos que atuam com a organização e circulação da informação. Nesse sentido, levanta outra questão, um pouco marginal, mas ainda assim pertinente: estará a formação e a preparação dos profissionais da informação à altura de enfrentar esses desafios? 